\title{
DOS ESPECIES NUEVAS DE PINGUICULA (LENTIBULARIACEAE) DE LA SIERRA MADRE ORIENTAL, MÉXICO*
}

\author{
SERgio Zamudio \\ Instituto de Ecología, A.C., Centro Regional del Bajío, Apdo. postal 386, \\ 61600 Pátzcuaro, Michoacán, México
}

\section{RESUMEN}

Se describen e ilustran dos nuevas especies de Pinguicula de la Sierra Madre Oriental, México: Pinguicula ibarrae de las cercanías de Tlanchinol, Hidalgo, que se incluye en la sección Heterophyllum y Pinguicula martinezii del Llano Chiquito, Querétaro, de la sección Agnata, ambas del subgénero Isoloba. Se enfatiza la gran diversidad de Pinguicula existente en la provincia fisiográfica de la Sierra Madre Oriental, que la hace la región que concentra el mayor número de especies de este género en el mundo. También se señala la tendencia de algunas especies mexicanas a habitar en los matorrales desérticos y el bosque tropical caducifolio.

Palabras clave: Lentibulariaceae, México, Pinguicula.

\begin{abstract}
Two new species of Pinguicula from the Sierra Madre Oriental, Mexico, are described and illustrated. Pinguicula ibarrae from the vicinity of Tlanchinol, Hidalgo, belongs to the section Heterophyllum, and Pinguicula martinezii from Llano Chiquito, Queretaro, is in the section Agnata, both of subgenus Isoloba. Emphasis is placed on the great diversity of Pinguicula found in the physiographic province of the Sierra Madre Oriental, which concentrates the largest amount of species on a world-wide scale. Emphasis is also placed on the tendency of some Mexican species to inhabit desertscrub and tropical deciduous forest.
\end{abstract}

Key words: Lentibulariaceae, Mexico, Pinguicula.

*Trabajo realizado con apoyo económico del Instituto de Ecología, A. C. (cuenta 902-07), del Consejo Nacional de Ciencia y Tecnología y de la Comisión Nacional para el Conocimiento y Uso de la Biodiversidad. 
Exploraciones recientes en diferentes localidades de la Sierra Madre Oriental en los estados de Hidalgo y Querétaro han conducido al descubrimiento de dos nuevas especies de Pinguicula del subgénero Isoloba Barnhart, relacionadas con las secciones Agnata y Heterophyllum, de acuerdo con Casper $(1963,1966)$. A continuación se describen las nuevas entidades y se discuten sus afinidades.

Pinguicula ibarrae Zamudio sp. nov. Figs. 1 y 2.

Herba perennis; rhizoma simplex brevis, radicibus adventitiis numerosis filiformibus; folia radicalia rosulata, biformia; "hiemalia" 11-20, crassa, spathulata vel elliptica, 12-25 mm longa, 7-12.5 $\mathrm{mm}$ lata, apice obtusa vel rotundata, superne glandulis stipitatis dense vestita; "aestivalia" (8)10-20, membranacea, solum adpressa, obovato-spathulata, 35-95 $\mathrm{mm}$ longa, 15-45 $\mathrm{mm}$ lata, apice rotundata, margine involuta, laete viridia, superne glandulosa, glandulis sessilibus et glandulis stipitatis dense vestita; hibernacula nulla; pedunculi 5-12 erecti, pallide virides, glandulis stipitatis dense obsiti, 60-150 mm alti, uniflori; flores 24-35 mm longi (calcari incluso); calyx bilabiatus, laete viridis, extus et intus glandulis stipitatis dense obsitus; labium superum usque ad 1/2-2/3 longitudinis trilobum, lobis triangulatis vel ample ellipticis, 3.5-6 mm longis, $2-5 \mathrm{~mm}$ latis; labium inferum usque ad 1/2-2/3 longitudinis bilobum, lobis oblongo-ellipticis vel anguste ellipticis, acutis, $3-5 \mathrm{~mm}$ longis, $1.5-3 \mathrm{~mm}$ latis; corolla subisoloba, albida vel albida cum margine lilacina et faucibus violaceomaculatis, extus glandulis stipitatis disperse vestita; lobis subaequalibus, obovatis vel oblongis, basin versus subcuneatis, longioribus quam latioribus, apice rotundatis vel truncatis, 7-14 mm longis, 5-12 mm latis, superne pilis longis cylindricis dense vestitis; tubus subcylindricus, luteo-viridis, basin versus leviter angustatus, $8-15 \mathrm{~mm}$ longus, 5-9 mm latus, extus glandulis stipitatis disperse obsitus, intus pilosus, pilis longis cylindricis et pilis longis clavatis subcapitatis, sine palato; calcar subcylindricum, obtusum, anguste angulato-ovatum, 4.5-8 mm longum, 1.5-2.6 mm latum, cum tubo angulum obtusum $\left(130-160^{\circ}\right)$ formans; ovarium subglobosum, glandulis stipitatis parvulis obsitum; stigma bilabiatum, album, labio infero superiorem superanti, suborbiculato, fimbriato; capsula subglobosa, 4-5 mm longa, 3-4 mm lata, glandulis stipitatis disperse obsita; semina numerosa, fusiformia, minutissima, $\pm 1 \mathrm{~mm}$ longa, $\pm 0.25 \mathrm{~mm}$ lata; pollinis granula (4)5-colporata.

Planta herbácea perenne; rizoma simple, corto, raíces adventicias filiformes numerosas; hojas biformes, agrupadas en rosetas basales; roseta de "invierno" compacta, de 25 a $50 \mathrm{~mm}$ de diámetro, formada por 11 a 20 hojas carnosas, espatuladas a elípticas, de 12 a $25 \mathrm{~mm}$ de largo, por 7 a $12.5 \mathrm{~mm}$ de ancho, ápice obtuso a redondeado, densamente cubiertas con glándulas estipitadas en el haz; 

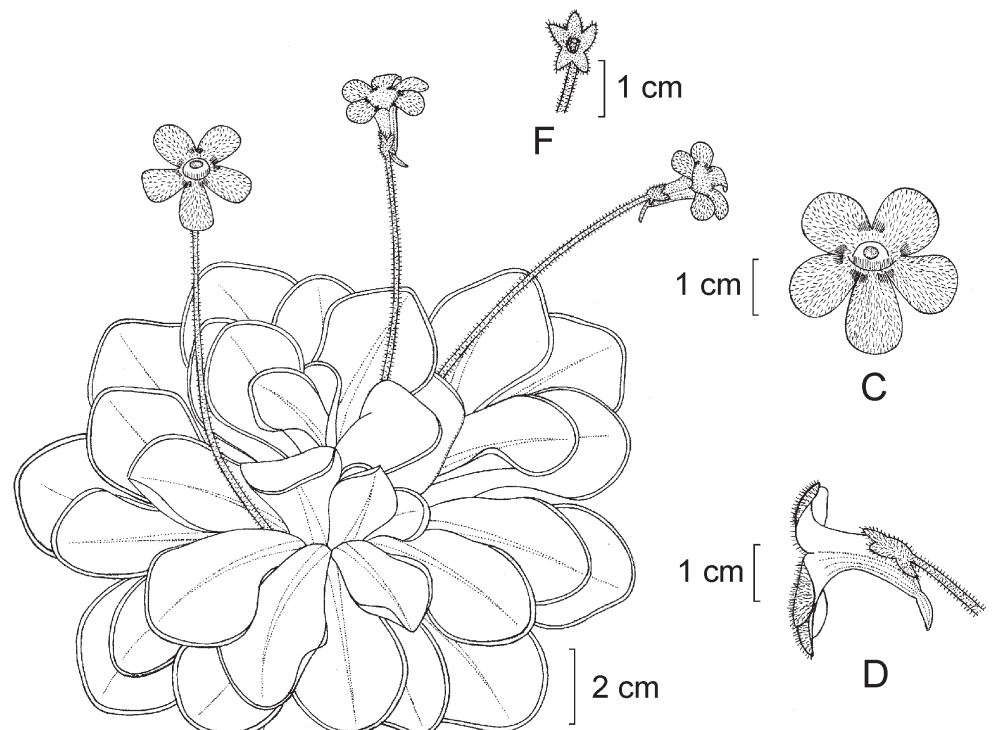
A
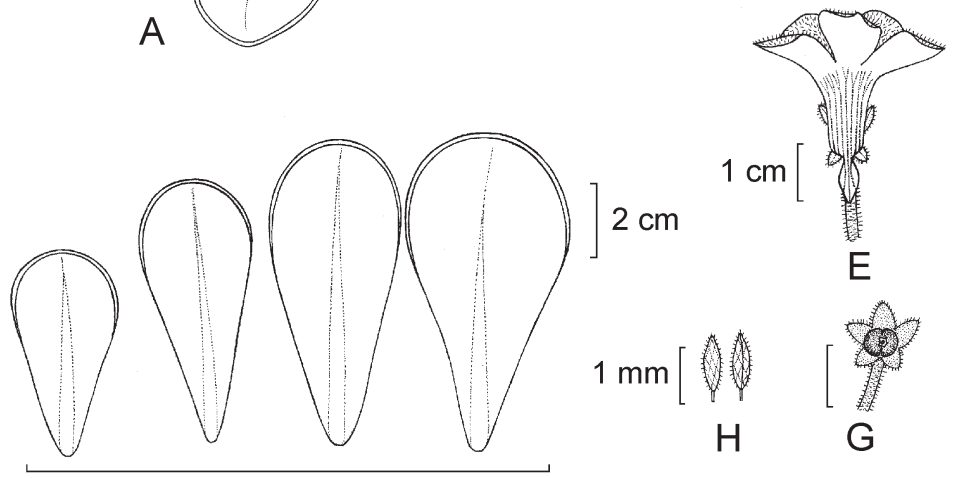

B
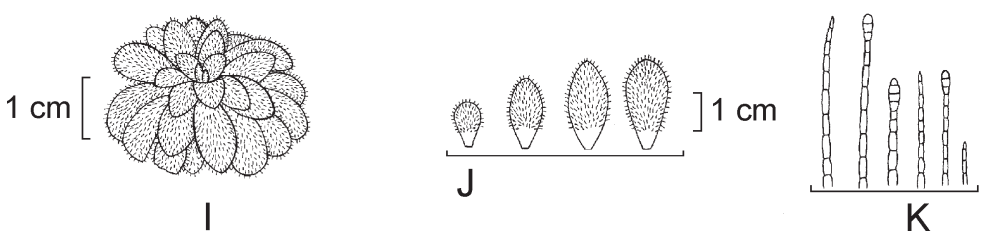

Fig. 1. Pinguicula ibarrae Zamudio. A. Hábito de la planta con hojas de "verano" y flores; B. Serie de hojas de "verano"; C. Flor vista de frente; D. Flor vista de lado; E. Vista anterior de la flor; F. Cáliz; G. Cáliz con fruto; H. Semillas; I. Roseta de "invierno"; J. Serie de hojas de "invierno"; K. Pelos de la corola. Dibujo de Rogelio Cárdenas. 

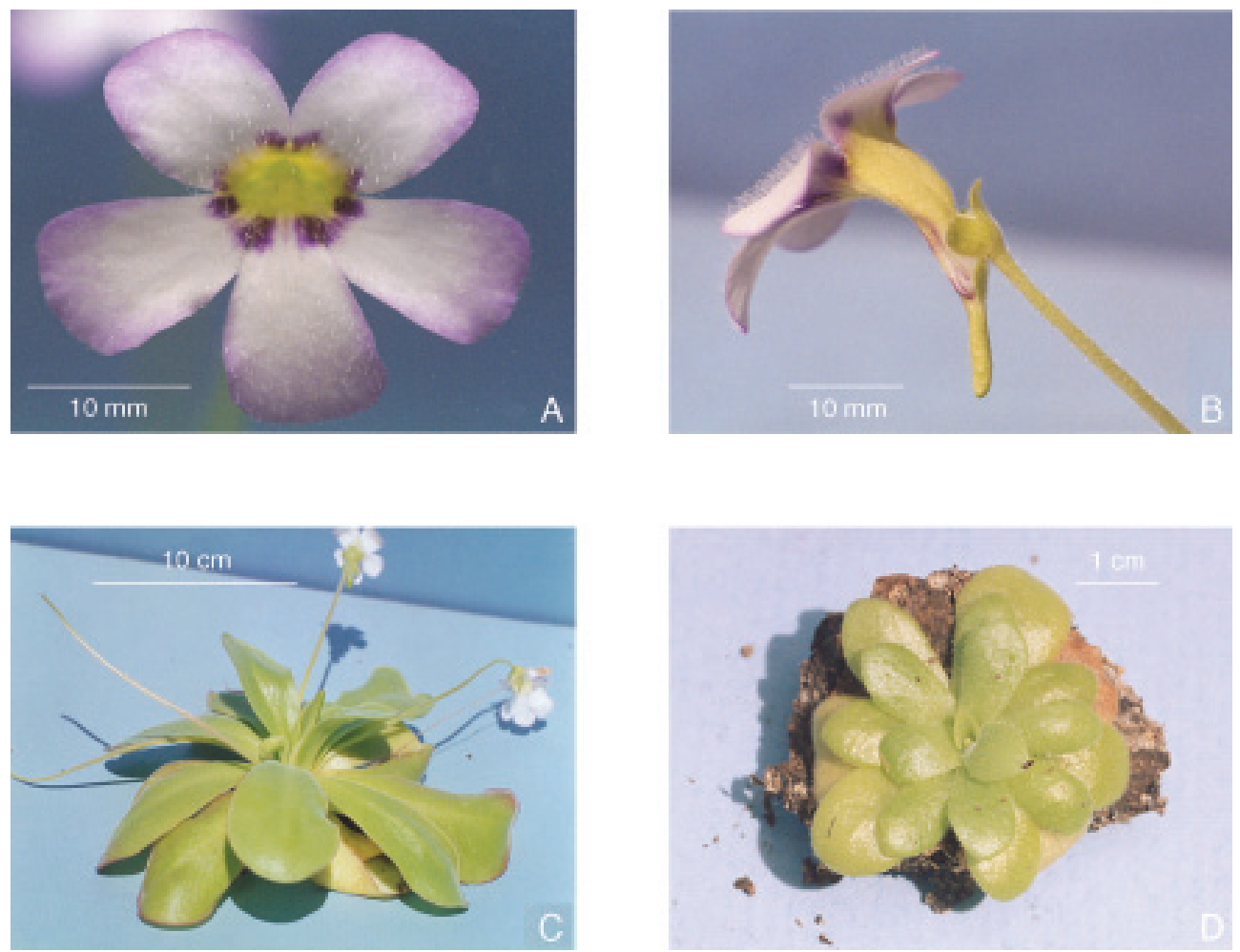

Fig. 2. Pinguicula ibarrae Zamudio. A. Flor muy colorida vista de frente; B. Flor vista de lado, se aprecia la pubescencia de la cara interna de los lóbulos de la corola y el espolón largo; C. Planta con hojas de "verano" y flores; D. Planta con hojas de "invierno".

rosetas de "verano" de 6 a $18 \mathrm{~cm}$ de diámetro, formadas por (8)10 a 20 hojas membranáceas, adpresas al suelo, de color verde pálido, obovado-espatuladas, de 35 a $95 \mathrm{~mm}$ de largo, por 15 a $45 \mathrm{~mm}$ de ancho, redondeadas en el ápice, margen involuto, glandulosas en las $2 / 3$ partes de la cara superior, cubiertas densamente con glándulas sésiles y glándulas estipitadas; hibernáculo ausente; pedúnculos 5 a 12 por temporada de floración, erectos, de 60 a $150 \mathrm{~mm}$ de altura, $\pm 4 \mathrm{~mm}$ de diámetro, verdes pálidos, cubiertos densamente con glándulas estipitadas de 0.5 a $1 \mathrm{~mm}$ de largo, así como de glándulas sésiles, unifloros; flores de 24. a $35 \mathrm{~mm}$ de largo (incluyendo el espolón); cáliz bilabiado, verde brillante, cubierto con glándulas estipitadas en ambas caras; labio superior trilobado, dividido hasta $1 / 2$ o $2 / 3$ de su longitud, lóbulos triangulares a ampliamente elípticos, agudos, de 3.5 a $6 \mathrm{~mm}$ de largo, 2 a $5 \mathrm{~mm}$ de ancho; labio inferior bilobado, dividido hasta $1 / 2$ o $2 / 3$ de su longitud, lóbulos oblongo-elípticos a angostamente elípticos, agudos, de 3 a $5 \mathrm{~mm}$ de largo, 
1.5 a $3 \mathrm{~mm}$ de ancho; corola subisoloba, variando en color de blanca a blanca con el margen lila y a veces con dos manchas de color violeta en la base de cada lóbulo, alrededor de la garganta; lóbulos subiguales, obovados a oblongos, subcuneados en la base, más largos que anchos, ápice redondeado o truncado, de 7 a $14 \mathrm{~mm}$ de largo, 5 a $12 \mathrm{~mm}$ de ancho, esparcidamente cubiertos con glándulas estipitadas cortas en la cara externa y densamente cubierta con pelos cilíndricos largos (de 1 a $2 \mathrm{~mm}$ ), claviformes o subcapitados, en la cara interna; garganta amplia, pilosa; tubo subcilíndrico, verde-amarillento, angostándose ligeramente hacia la base, de 8 a $15 \mathrm{~mm}$ de largo, 5 a $9 \mathrm{~mm}$ de ancho, cubierto por fuera con glándulas estipitadas dispersas, piloso por dentro, hasta la mitad, con largos pelos cilíndricos claviformes o subcapitados, que se hacen más cortos y gruesos hacia la base; sin paladar; espolón subcilíndrico en vista lateral, subrómbico en vista ventral, obtuso, de 4.5 a $8 \mathrm{~mm}$ de largo, 1.5 a $2.6 \mathrm{~mm}$ de ancho, formando un ángulo obtuso (130-160 ) con el tubo; ovario subgloboso, cubierto con pequeñas glándulas estipitadas; estigma bilabiado, blanco, el labio inferior más grande que el superior, suborbicular, fimbriado; cápsula subglobosa, de 4 a $5 \mathrm{~mm}$ de largo, por $3 \mathrm{a} 4 \mathrm{~mm}$ de ancho, cubierta con glándulas estipitadas dispersas; semillas numerosas, elipsoidales, $\pm 1 \mathrm{~mm}$ de largo, por $\pm 0.25 \mathrm{~mm}$ de ancho; polen (4)5-colporado.

Tipo: México, Hidalgo, municipio de Tlanchinol, $\pm 11 \mathrm{~km}$ al $\mathrm{N}$ de Tlanchinol, por la carretera a Huejutla, 18.XI.2001, S. Zamudio, A. Ibarra y E. Zamudio 11814 (IEB).

Ejemplares adicionales revisados: México, Hidalgo, municipio de Tlanchinol, $\pm 13 \mathrm{~km}$ al NE de Tlanchinol por la carretera a Huejutla, 21.III.2003, S. Zamudio y A. Ibarra 12321 (IEB); along Hwy. 105 between Pachuca and Tampico, 1823 miles S of Huejutla, $20^{\circ} 59^{\prime} \mathrm{N}, 98^{\circ} 31^{\prime}$ W, 28.II.1987, T. B. Croat y D. P. Hannon 65992 (ENCB, IEB, MO).

Fenología: Las plantas florecen de septiembre a marzo, principalmente durante los meses invernales; en el campo se han observado con flores y hojas de verano bien desarrolladas en noviembre, mientras que en febrero y marzo se colectaron todavía con flores y hojas de verano más cortas. En cultivo las plantas que se mantienen con riego en lugares frescos y sombreados florecen y conservan las hojas de verano durante todo el año. A su vez, en las que han sido sometidas a sequía extrema durante el invierno, se forman rosetas de resistencia compactas, con 11 a 20 hojas carnosas, espatuladas y con la superficie superior cubierta densamente con pelos blancos no carnívoros, que no se han observado en campo. Por lo anterior se sospecha que si en el ambiente prevalece humedad constante durante todo el año, no se forman las rosetas de invierno o éstas se originan tardíamente, en comparación 
con otras especies en las que desde noviembre se empiezan a formar tales conjuntos de hojas.

Hábitat: Las plantas de esta especie crecen en taludes o laderas muy inclinadas de rocas lutitas del Terciario Inferior, con orientación norte, entre el bosque mesófilo de montaña muy perturbado, compuesto por Liquidambar styraciflua, Clethra sp. y Quercus spp., o en su transición con el bosque tropical perennifolio, entre 900 y $1100 \mathrm{~m}$ de altitud.

Pinguicula ibarrae se ubica en la sección Heterophyllum, del subgénero Isoloba de acuerdo con Casper (1966), por presentar dos tipos de hojas en rosetas subsecuentes durante el ciclo anual, corola isoloba con los lóbulos enteros, el tubo cilíndrico sin paladar y espolón más largo que ancho, formando un ángulo distinto con respecto al tubo.

A primera vista, la especie nueva muestra cierta similitud con Pinguicula agnata Casper, sin embargo, la formación de rosetas de "invierno" bien diferenciadas y las hojas de "verano" membranáceas, con el margen ligeramente involuto las separa de esta última con facilidad.

Es más parecida a Pinguicula pilosa Luhrs, Studnicka et Gluch (Luhrs, Studnicka y Gluch, 2004, Fig. 3), con la que comparte las hojas de "verano" membranáceas con el margen involuto; sin embargo, las plantas de Pinguicula ibarrae son más grandes que las de $P$. pilosa, de la que además se diferencian por las rosetas de "verano" formadas por 8 a 20 hojas obovado-espatuladas, más de dos veces más largas que anchas, de 35 a $95 \mathrm{~mm}$ de largo, por 15 a $45 \mathrm{~mm}$ de ancho (Fig. 2C), mientras que en P. pilosa están compuestas sólo por 8 a 12 hojas ampliamente ovadas a suborbiculares, de 25 a $40 \mathrm{~mm}$ de largo, por 20 a $30 \mathrm{~mm}$ de ancho (Fig. 3C).

El pedúnculo floral de $P$. ibarrae mide de 50 a $150 \mathrm{~mm}$ de largo y está densamente cubierto por glándulas estipitadas menores de $1 \mathrm{~mm}$ (Fig. 2B), en tanto que en $P$. pilosa el pedúnculo es más corto, de 35 a $90 \mathrm{~mm}$ de largo y está cubierto por dos tipos de pelos, una capa densa de pelos glandulares estipitados alternando con pelos subulados más largos y espaciados (Fig. 3B).

La flor es mayor en $P$. ibarrae, pues mide de 24 a $35 \mathrm{~mm}$ (incluyendo el espolón), el tubo es de 8 a $15 \mathrm{~mm}$ de largo y el espolón de 4.5 a $8 \mathrm{~mm}$ de largo, recto, formando un ángulo obtuso $\left(130-160^{\circ}\right)$ con el tubo de la corola (Fig. 2A y B); mientras que en P. pilosa las flores son de 16 a $25 \mathrm{~mm}$ de largo (incluyendo el espolón), el tubo va de 6 a $7 \mathrm{~mm}$ de largo, el espolón de 4 a $5 \mathrm{~mm}$ de largo, es incurvado y forma un ángulo de \pm 90 con respecto al tubo (Figs. 3A y B). El espolón corto e incurvado permite diferenciarlas con facilidad. 

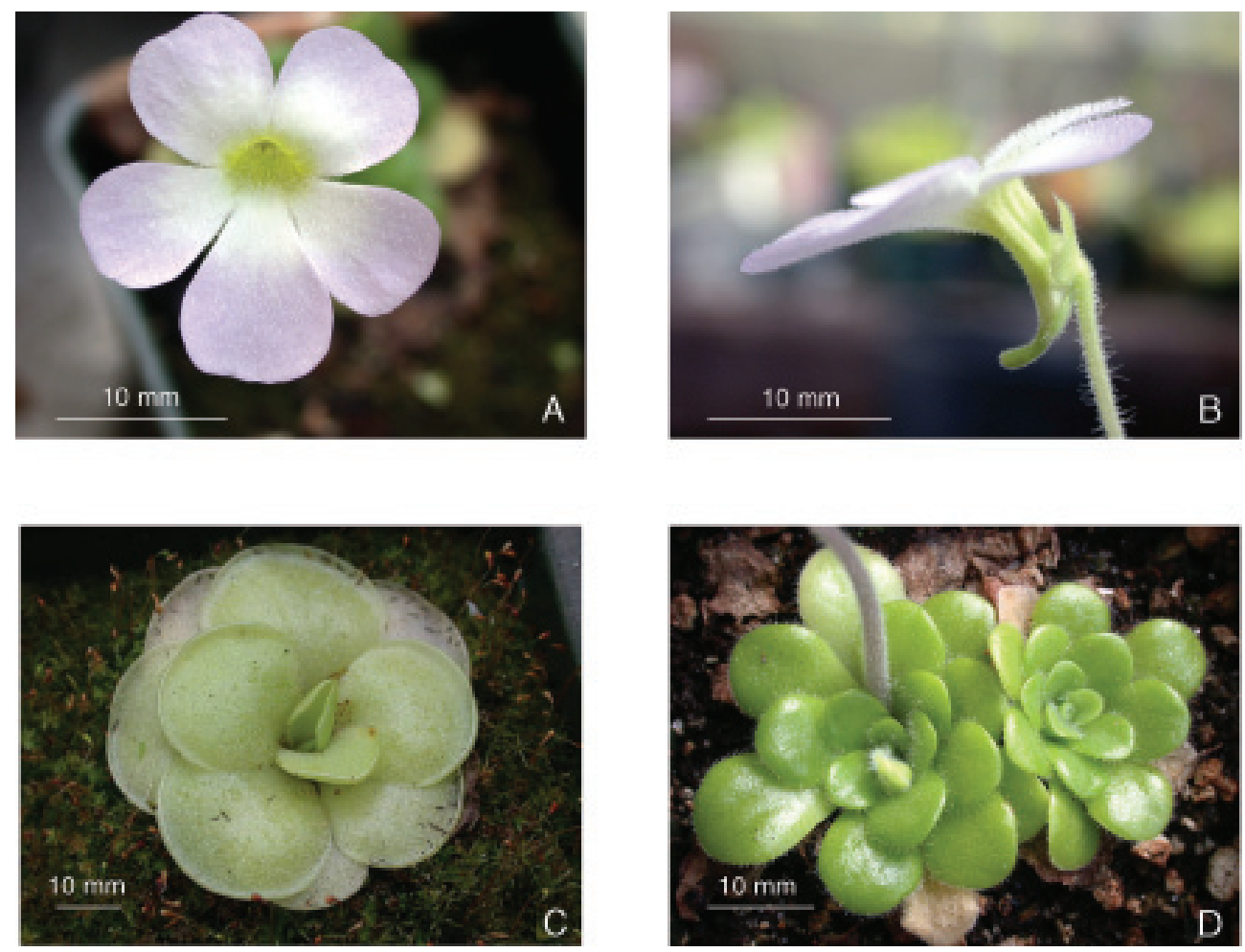

Fig. 3. Pinguicula pilosa Luhrs, Studnicka et Gluch. A. Flor vista de frente; B. Flor vista de lado, destaca el espolón corto y curvado y la pubescencia del pedúnculo y el cáliz formada por dos tipos de pelos; C. Planta con hojas de "verano"; D. Planta con hojas de “invierno". Fotografías de Edward Read.

Con respecto a la roseta de "invierno", en $P$. ibarrae tal estructura no se forma o se origina tardíamente dependiendo de la humedad prevaleciente en el ambiente; mientras que en $P$. pilosa la producción de rosetas de "invierno" es constante.

El ambiente que ocupan también es diferente; mientras que $P$. ibarrae habita en laderas muy inclinadas de rocas lutitas, en el bosque mesófilo de montaña, entre 900 y $1100 \mathrm{~m}$ de altitud, $P$. pilosa se conoce de laderas de rocas calizas entre el matorral submontano o el bosque de encinos.

Etimología: El nombre de la especie se dedica al Sr. Adolfo Ibarra Vázquez, entusiasta cultivador de plantas carnívoras, quien fue una de las primeras personas que colectó y cultivó individuos de esta especie. 
Pinguicula martinezii Zamudio sp. nov. Figs. 4 y 5.

Herba perennis; rhizoma simplex brevis, radicibus adventitiis numerosis filiformibus; folia radicalia rosulata, biformia, "hiemalia" (16)20-38, crassa, spathulata vel oblongo-spathulata, 8-30(40) $\mathrm{mm}$ longa, 3.5-15 mm lata, apice obtusa, superne versus apicem dense vestita cum pilis multicellularibus albis; "aestivalia" (6)8-14, erecta, anguste-spathulata, 50-100 mm longa, 13-25 mm lata, apice obtusa, margine non involuta, laete viridia, superne glandulosa, glandulis sessilibus et glandulis stipitatis dense vestita; hibernacula nulla; pedunculli 1-4 erecti, pallide viridi, glandulis stipitatis dense obsiti, 60-115 mm alti, uniflori; flores 13-25(30) mm longi (calcari incluso); calyx bilabiatus, laete viridis, extus et intus glandulis stipitatis dense obsitus; labium superum usque ad 1/2-2/3 longitudinis trilobum, lobis triangulatis vel oblongis, 2-4 mm longis, 2-2.7 mm latis; labium inferum usque ad 1/2-2/3 longitudinis bilobum, lobis triangulatis vel ellipticis, $1.5-2.5 \mathrm{~mm}$ longis, $1.5-2 \mathrm{~mm}$ latis; corolla subisoloba, labio infero superiorem paulo superanti, albida vel lilacino-marginata et in faucibus violaceo-maculata, extus glandulis stipitatis disperse vestita; lobis subaequalibus, oblongis, obovatis vel ample obovatis, basin versus subcuneatis, apice rotundatis, superiore 4-13 mm longo, 4.7-12 mm lato, inferiore 4-14 mm longo, 4-12 mm lato, superne pilis longis cylindricis disperse vestitis; tubus subcylindricus, faux ample basin versus leviter angustatus, paulum dorso-ventraliter compressus, sine palato, viridis vel luteo-viridis, 5.5-11 mm longus, 4.5-7 mm latus, extus glandulis stipitatis disperse obsitus, intus pilosus, pilis longis clavatis dense vestitus, basin tubi versus pilis brevioribus; calcar subcylindricum, angulato obtusum, 2.5-5 mm longum, 1.2-2.5 mm latum, cum tubo angulum obtusum $\left(130-160^{\circ}\right)$ formans; ovarium subglobosum, glandulis stipitatis parvulis obsitum; stigma bilabiatum, album, labio infero superiorem superanti, suborbiculato, fimbriato; capsula subglobosa, 4-5 mm longa, 3-4 $\mathrm{mm}$ lata, glandulis stipitatis disperse obsita; semina numerosa, ellipsoidali-fusiformia, minutissima, $\pm 1 \mathrm{~mm}$ longa, $\pm 0.25 \mathrm{~mm}$ lata; pollinis granula 4-5-colporata; florescentia II-IV.

Planta herbácea perenne; rizoma simple, corto, con numerosas raíces adventicias filiformes; hojas dimórficas, agrupadas en rosetas basales subsecuentes, roseta de "invierno" compacta, de 20 a 50(60) mm de diámetro, formada por (16)20 a 38 hojas carnosas, espatuladas a oblongo-espatuladas, de 8 a 30(40) $\mathrm{mm}$ de largo, 3.5 a $15 \mathrm{~mm}$ de ancho, obtusas en el ápice, cubiertas densamente en la mitad apical con pelos glandulares blancos; roseta de "verano" de (8)10 a $16 \mathrm{~cm}$ de diámetro, formada por (6)8 a 14 hojas, erectas, angostamente espatuladas, de 50 a $100 \mathrm{~mm}$ de largo, por 13 a $25 \mathrm{~mm}$ de ancho, obtusas en el ápice, margen no involuto, verdes, a veces teñidas de púrpura, cubiertas densamente en la cara superior con glándulas sésiles y glándulas estipitadas; hibernáculo ausente; pedúnculos 1 a 4 por temporada de floración, erectos, de 60 a $115 \mathrm{~mm}$ de alto, verdes pálidos o teñidos de color 

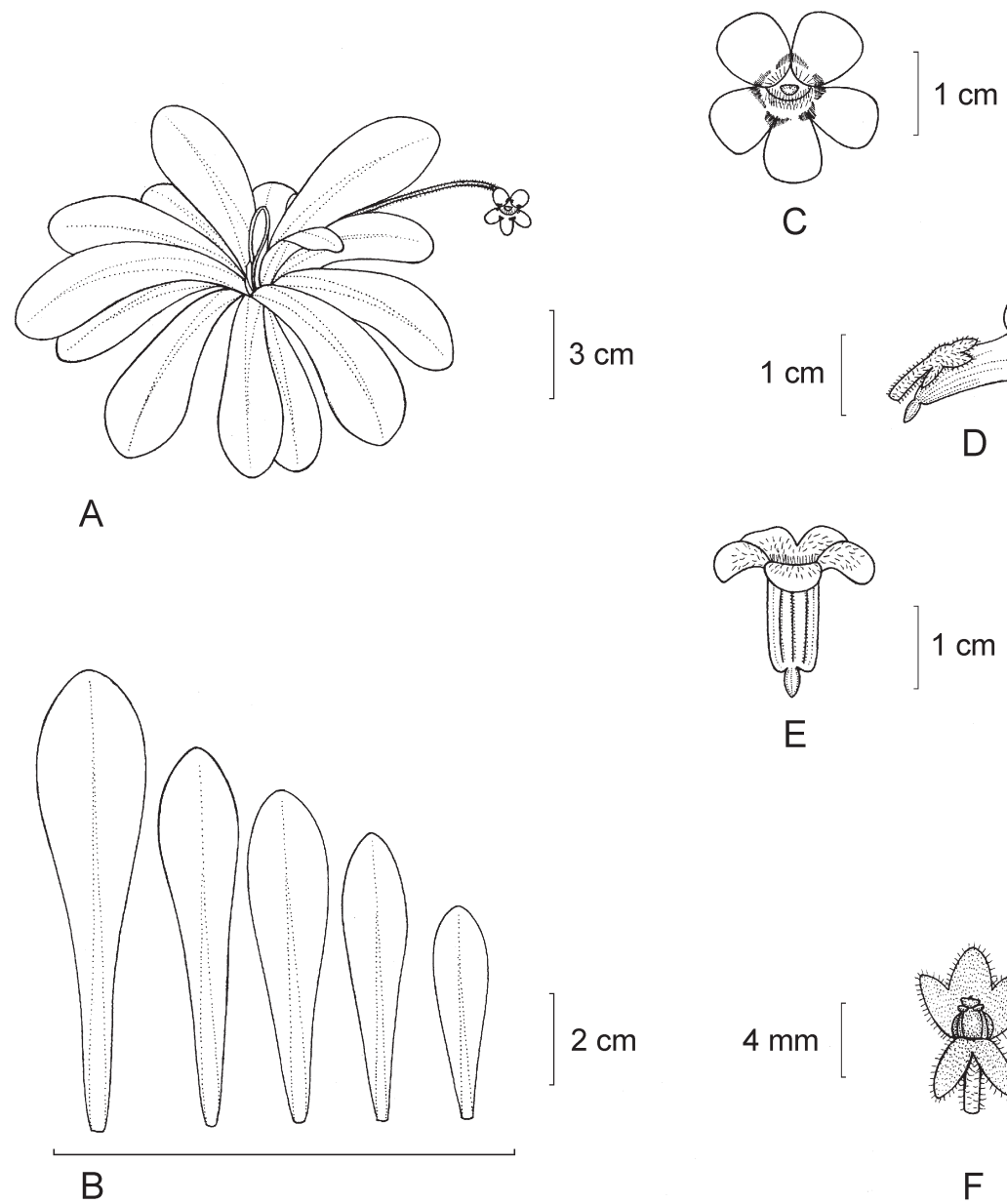

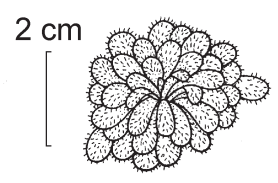

G

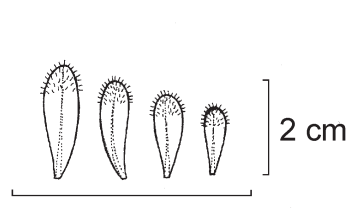

$\mathrm{H}$

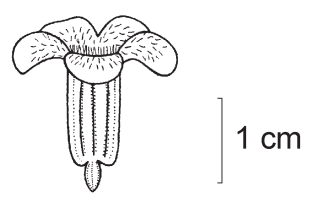

$\mathrm{E}$
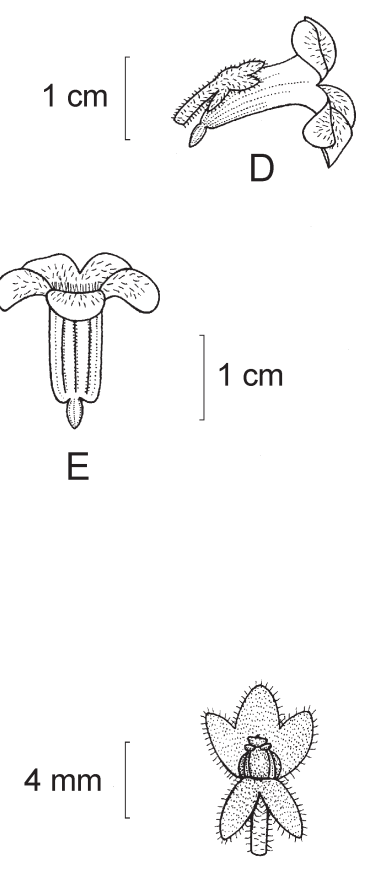

$\mathrm{F}$

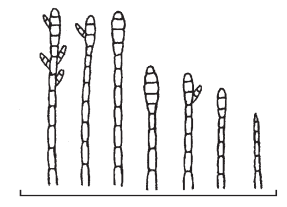

।

Fig. 4. Pinguicula martinezii Zamudio. A. Hábito de la planta con hojas de "verano"; B. Serie de hojas de "verano"; C. Vista frontal de la flor; D. Vista lateral de la flor; E. Vista ventral de la flor; F. Cáliz; G. Roseta de "invierno"; H. Serie de hojas de "invierno"; I. Pelos del interior de la corola. Dibujo de Rogelio Cárdenas. 

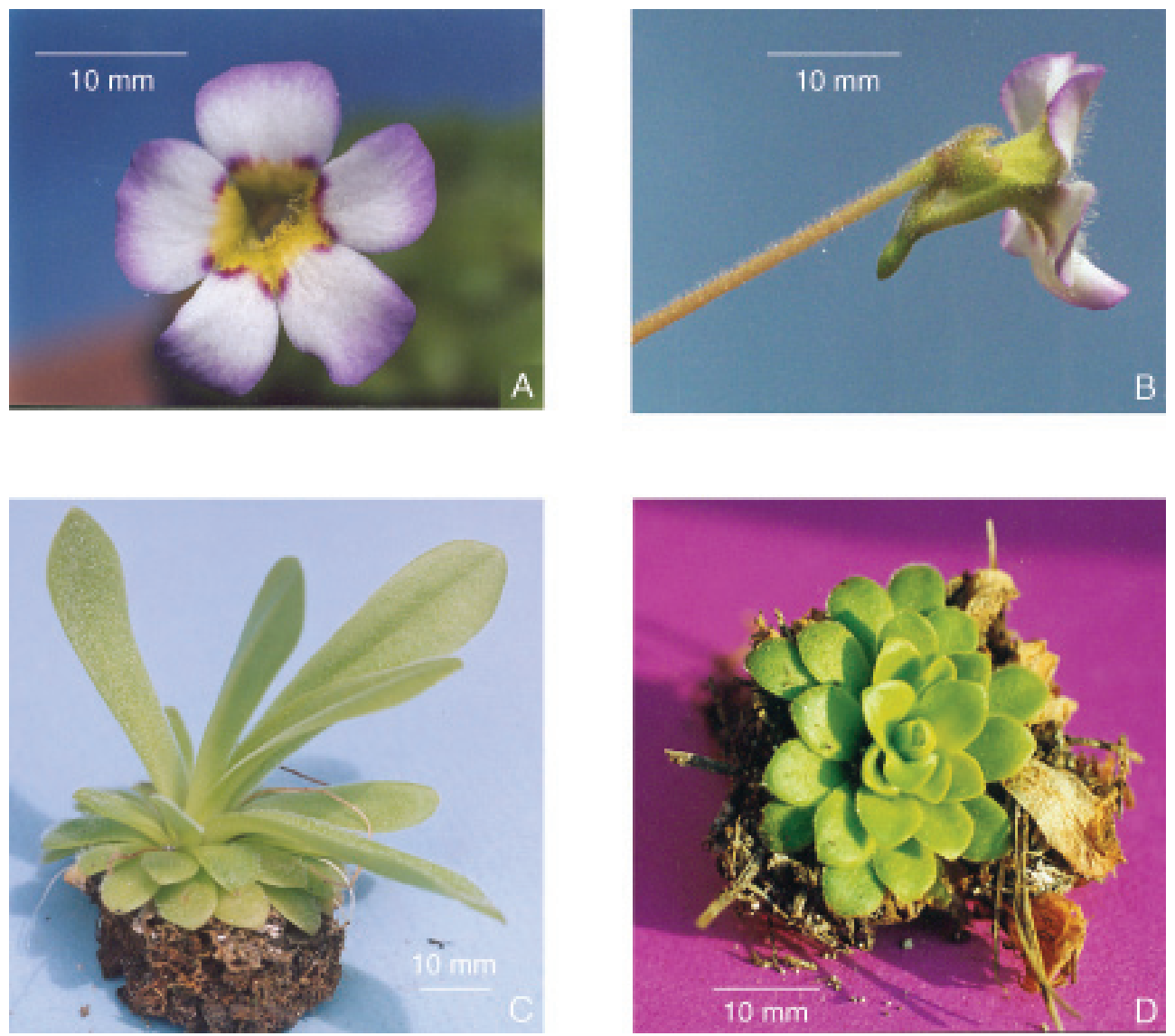

Fig. 5. Pinguicula martinezii Zamudio. A. Flor muy colorida vista de frente; B. Flor vista de lado; C. Planta con hojas de "verano" jóvenes surgiendo del centro de la roseta de "invierno"; D. Planta con hojas de "invierno".

púrpura, cubiertos densamente con glándulas estipitadas de 0.5 a $1 \mathrm{~mm}$ de largo, unifloros; flores de 13 a 25(30) mm de largo (incluyendo el espolón); cáliz bilabiado, verde, cubierto con glándulas estipitadas en ambas caras; labio superior trilobado, dividido hasta $1 / 2$ o $2 / 3$ de su longitud, lóbulos triangulares a oblongos, de 2 a $4 \mathrm{~mm}$ de largo, 2 a $2.7 \mathrm{~mm}$ de ancho; labio inferior bilobado, dividido hasta $1 / 2$ o 2/3 de su longitud, lóbulos triangulares a elípticos, de 1.5 a $2.5 \mathrm{~mm}$ de largo, 1.5 a $2 \mathrm{~mm}$ de ancho; corola subisoloba, el labio inferior un poco más grande que el superior, variando de color de completamente blanca a blanca con el margen de los lóbulos violáceo y con manchas de color violeta en la base de los lóbulos que rodean la garganta, cubierta con glándulas estipitadas cortas en la cara externa y con largos 
pelos claviformes dispersos en la mitad inferior de la cara superior, lóbulos oblongos, obovados a ampliamente obovados, subcuneados en la base, redondeados en el ápice, los superiores de 4 a $13 \mathrm{~mm}$ de largo y 4.7 a $12 \mathrm{~mm}$ de ancho, los inferiores de 4 a $14 \mathrm{~mm}$ de largo, 4 a $12 \mathrm{~mm}$ de ancho, garganta verde o amarillo-verdosa, cubierta densamente con pelos claviformes; tubo subcilíndrico, algo comprimido dorsoventralmente, angostándose ligeramente hacia la base, verde o verde-amarillento, de 5.5 a $11 \mathrm{~mm}$ de largo, 4.5 a $7 \mathrm{~mm}$ de ancho, cubierto por fuera con glándulas estipitadas cortas, piloso por dentro con largos pelos cilíndricos y pelos claviformes, que disminuyen de tamaño hacia la base del tubo; sin paladar; espolón subcilíndrico, angulado, obtuso, de 2.5 a $5 \mathrm{~mm}$ de largo, 1.2 a $2.5 \mathrm{~mm}$ de ancho, de color verde claro, formando un ángulo obtuso $\left(130-160^{\circ}\right)$ con el tubo; ovario subgloboso, cubierto con pequeñas glándulas estipitadas; estigma bilabiado, blanco, el labio inferior más grande que el superior, suborbicular, fimbriado; cápsula subglobosa, de 4 a $5 \mathrm{~mm}$ de largo, por 3 a $4 \mathrm{~mm}$ de ancho, cubierta con glándulas estipitadas dispersas; semillas numerosas, elipsoidales (fusiformes), de $\pm 1 \mathrm{~mm}$ de largo, por $\pm 0.25 \mathrm{~mm}$ de ancho; polen 4-5-colporado.

Tipo: México, Querétaro, municipio de Landa de Matamoros, Llano Chiquito. 17.II.1989, S. Zamudio y E. Carranza 7150 (IEB).

Material adicional observado: México, Querétaro, municipio de Landa de Matamoros, Llano Chiquito, 1-2.IV.1997, S. Zamudio y E. Carranza 10221 (IEB); Ibid., 28.II.2004, S. Zamudio y A. Ibarra 12713 (IEB); puerto entre el Llano del Conejo y el Llano Chiquito, 13.X.1999, S. Zamudio y E. Carranza 11183 (IEB) (material estéril).

Fenología: Se ha colectado con flores y rosetas de "invierno" en los meses de febrero y marzo, pero la floración se puede prolongar hasta principios de abril; las rosetas de "verano" se desarrollan de mayo a septiembre y en octubre empiezan a formarse las nuevas rosetas de "invierno".

Hábitat: Crece sobre rocas calizas en riscos, taludes o laderas muy inclinadas, entre el bosque mesófilo de montaña compuesto por: Cupressus lusitanica, Oreopanax xalapensis, Pinus greggii, Prunus sp., Quercus affinis y Tilia mexicana, entre 2000 y 2370 m s.n.m.

Pinguicula martinezii pertenece al subgénero Isoloba, pero no está clara su ubicación dentro de las secciones descritas por Casper $(1963,1966)$ en la monografía del género Pinguicula. Por tener dos tipos de hojas en rosetas subsecuentes podría ser incluida en la sección Heterophyllum; sin embargo, muestra 
más parecido con Pinguicula agnata, con la que comparte la mayoría de sus caracteres, por lo que quedaría mejor ubicada en la sección Agnata, aunque no cumple completamente con la diagnosis de esta última, precisamente por presentar dos tipos de hojas en rosetas subsecuentes, dado que la sección está descrita como homófila. Un problema semejante se presentó en el caso de $P$. pilosa, especie que sus autores ubicaron en la sección Agnata a pesar de que presenta dos tipos de hojas. La ubicación correcta de ambas especies queda pendiente hasta que no se haga una revisión crítica de la delimitación de las secciones del subgénero Isoloba a la luz de los conocimientos acumulados en los años posteriores a la publicación de la monografía de Casper.

La especie nueva se distingue de Pinguicula agnata por las rosetas de "invierno" compactas con 16 a 38 hojas moderadamente carnosas, espatuladas a oblongo-espatuladas; la de "verano" formada por 6 a 14 hojas angostamente espatuladas, de 60 a $100 \mathrm{~mm}$ de largo, por 13 a $25 \mathrm{~mm}$ de ancho y las flores más chicas de 13 a 25(30) mm de largo (incluyendo el espolón). En cambio en P. agnata la roseta de "invierno" está constituida por 12 a 20 hojas carnosas más gruesas, espatuladas, con el ápice redondeado a obtuso; las hojas de "verano" son espatuladas a obovado-oblongas, de 35 a $110 \mathrm{~mm}$ de largo, por 15 a $50 \mathrm{~mm}$ de ancho; en tanto que la flor mide de 20 a $34 \mathrm{~mm}$ de largo (incluyendo al espolón).

El ambiente en que se desarrollan ambas especies es muy contrastante: $P$. martinezii crece en paredes verticales de rocas calizas en el bosque mesófilo de montaña, entre 2000 y $2370 \mathrm{~m}$ de altitud y $P$. agnata prospera en riscos o paredes de rocas calizas en bosque tropical caducifolio, matorral submontano o bosque de encinos, en una franja altitudinal que va de 350 a $2000 \mathrm{~m}$ de altitud.

Etimología: El nombre de la especie honra al Profesor Maximino Martínez (1888-1964), quien fue un extraordinario estudioso de las plantas mexicanas.

La descripción de estos dos taxa nuevos incrementa a cerca de 44 el número de especies de Pinguicula conocidas de México hasta el momento y no se descarta la posibilidad de que en el futuro sean descubiertas todavía algunas más. Se debe resaltar el hecho de que la Sierra Madre Oriental es la región fisiográfica y geológica del país en donde se concentra el mayor número de representantes del género, y que con la excepción de Pinguicula lilacina Schlecht. et Cham. y P. moranensis H.B.K., la mayoría de ellas son endemismos estrechos que crecen sobre rocas calizas, lutitas o yesos. La gran cantidad de especies registradas hasta ahora muestran la importancia que tiene esta región como un centro de alta diversidad del género en el país. En el Cuadro 1 se enlistan los miembros de Pinguicula que han sido citados para la Sierra Madre Oriental, señalando el sustrato en que se 
Cuadro 1. Especies de Pinguicula distribuidas en la Sierra Madre Oriental en México. Simbología de los tipos de vegetación: BCupr.= bosque de Cupressus; $\mathrm{BMM}=$ bosque mesófilo de montaña, $\mathrm{BP}=$ bosque de pinos; $\mathrm{BPQ}=$ bosque de pino-encino; $\mathrm{BQ}=$ bosque de encinos; $\mathrm{BTC}=$ bosque tropical caducifolio; $\mathrm{MR}=$ matorral desértico rosetófilo; $\mathrm{MS}=$ matorral submontano.

\begin{tabular}{|c|c|c|c|}
\hline Especie & Sustrato & $\begin{array}{l}\text { Tipo de vegetación e } \\
\text { intervalo altitudinal }\end{array}$ & $\begin{array}{l}\text { Distribución por } \\
\text { estados }\end{array}$ \\
\hline$P$. agnata Casper & caliza & $\begin{array}{l}\text { BQ, BTC, MS. } \\
350-2000 \mathrm{~m}\end{array}$ & Gto., Hgo., Qro. \\
\hline P. calderoniae Zamudio & caliza & BMM. 2060-2300 m & Qro., S.L.P. \\
\hline P. cyclosecta Casper & caliza & $\begin{array}{l}\text { BMM, BPQ, BQ. } \\
450-2050 \mathrm{~m}\end{array}$ & N.L., Tamps. \\
\hline P. debbertiana Speta et Fuchs & yeso & MR. $1800 \mathrm{~m}$ & S.L.P. \\
\hline P. elizabethiae Zamudio & caliza, lutita & MS. $1000-1600 \mathrm{~m}$ & Hgo., Qro. \\
\hline $\begin{array}{l}\text { P. emarginata Zamudio et } \\
\text { Rzedowski }\end{array}$ & caliza & BMM. 1400-1550 m & Pue., Ver. \\
\hline P. ehlersiae Speta et Fuchs & caliza & BQ. $1800-2000 \mathrm{~m}$ & N.L., S.L.P., Tamps. \\
\hline$P$. esseriana Speta et Fuchs & caliza & MS, BP. 1800-2350 m & Hgo., Qro., S.L.P. \\
\hline P. gracilis Zamudio & caliza & $\begin{array}{l}\text { BCupr., BQ } \\
1000-2150 \mathrm{~m}\end{array}$ & $\begin{array}{l}\text { Coah., N.L., } \\
\text { Tamps. }\end{array}$ \\
\hline P. gypsicola Brandegee & yeso & MS. $1300 \mathrm{~m}$ & N.L. \\
\hline P. ibarrae Zamudio & lutita & BMM. 900-1100 m & Hgo. \\
\hline P. immaculata Zamudio et Lux & yeso & MR. $1300-1400 \mathrm{~m}$ & S.L.P. \\
\hline P. jaumavensis Debbert & caliza & BQ. $1450-1470 \mathrm{~m}$ & Tamps. \\
\hline P. kondoi Casper & caliza & BP, MS. 1400-1900 m & N.L., S.L.P., Tamps. \\
\hline P. laxifolia Luhrs & caliza & BMM. 1900-2070 m & Tamps. \\
\hline P. lilacina Schlecht. et Cham. & $\begin{array}{l}\text { caliza, roca } \\
\text { ígnea }\end{array}$ & $\begin{array}{l}\text { BMM, BPQ, BQ. } \\
700-2400 \mathrm{~m}\end{array}$ & $\begin{array}{l}\text { Chis., Jal., Oax., } \\
\text { Qro., Sin., Tamps., } \\
\text { Ver., Guat., Hond. }\end{array}$ \\
\hline P. martinezii Zamudio & caliza & BMM. 2000-2370 m & Qro. \\
\hline $\begin{array}{l}\text { P. moctezumae Zamudio et } \\
\text { R. Z. Ortega }\end{array}$ & caliza & MS. $900-1000 \mathrm{~m}$ & Hgo., Qro. \\
\hline $\begin{array}{l}\text { P. moranensis H. B. K. } \\
\text { var. moranensis }\end{array}$ & $\begin{array}{l}\text { caliza, roca } \\
\text { ígnea }\end{array}$ & $\begin{array}{l}\text { BP, BMM, BQ. } \\
750-3200 \mathrm{~m}\end{array}$ & $\begin{array}{l}\text { Chis., Gro., Gto., } \\
\text { Hgo., Mex., Mich., } \\
\text { N.L., Oax., Qro., } \\
\text { S.L.P., Tamps., } \\
\text { Ver., Guat. }\end{array}$ \\
\hline
\end{tabular}


Cuadro 1. Continuación.

\begin{tabular}{|l|l|l|l|}
\hline \multicolumn{1}{|c|}{ Especie } & \multicolumn{1}{|c|}{ Sustrato } & $\begin{array}{c}\text { Tipo de vegetación e } \\
\text { intervalo altitudinal }\end{array}$ & $\begin{array}{c}\text { Distribución por } \\
\text { estados }\end{array}$ \\
\hline $\begin{array}{l}\text { P. pilosa } \text { Luhrs, Studnicka } \\
\text { et Gluch }\end{array}$ & caliza & MS?, BQ? & Tamps. \\
\hline $\begin{array}{l}P . \text { rotundiflora } \text { Studnicka } \\
\text { P. takakii Zamudio et } \\
\text { Rzedowski }\end{array}$ & yeso & $\begin{array}{l}\text { BPQ, MS. } \\
1025-2135 \mathrm{~m}\end{array}$ & N.L., Tamps. \\
\hline
\end{tabular}

desarrollan, el tipo de vegetación, el intervalo altitudinal en que crecen y los estados en donde se distribuyen.

Aunque aún existen dudas sobre la identidad correcta de $P$. jaumavensis Debbert que habrá que resolver, destaca el alto número de especies que habitan en esta región, lo que significa que la mayor concentración de especies de Pinguicula en el mundo se encuentra en la Sierra Madre Oriental en México.

En el cuadro anterior se puede apreciar que a pesar de que el grueso de los taxa que crecen sobre sustrato de rocas calizas habitan en sitios con bosques de encino, pino-encino o mesófilo de montaña, algunos como Pinguicula elizabethiae, $P$. esseriana y $P$. moctezumae se han adaptado a vivir en matorrales xerófilos o en su transición con bosques también xerófilos de pino y/o encino. Además destaca el hecho de que las cinco especies que se encuentran exclusivamente sobre suelos yesosos crecen en matorrales xerófilos, principalmente en el matorral desértico rosetófilo y en el matorral submontano.

La tendencia de algunas de las especies de Pinguicula mexicanas a crecer en suelos yesosos y su asociación con los matorrales xerófilos y el bosque tropical caducifolio ya había sido señalada por Zamudio y Lux (1992), cuando describieron Pinguicula immaculata. Estos autores mencionan que debido a que este sustrato es poco frecuente en México y a que sus afloramientos se encuentran dispersos, muy lejos unos de otros, tales especies representan ejemplos claros de microendemismos.

Es de particular importancia resaltar que la tendencia entre las especies mexicanas a ocupar ambientes secos o semisecos con vegetación de matorral xerófilo o bosque tropical caducifolio, es un hecho único en la evolución del género Pinguicula, que refleja un largo período de adaptación a las condiciones climáticas particulares del país; quizás esto explique el porqué las hojas de verano de algunas especies mexicanas presentan características de suculencia (Studnicka, 1991). Lo señalado contrasta con el comportamiento de la mayoría de las especies del género, 
que prefieren sitos con mayor humedad o incluso inundados a lo largo del año en regiones con clima más fresco y húmedo.

\section{AGRADECIMIENTOS}

Deseo manifestar mi más sincero agradecimiento a Eleazar Carranza por su ayuda en la colecta de ejemplares, a Adolfo Ibarra por compartir conmigo su material y por su compañía en el campo. Asimismo debo agradecer a Edward Read por la información proporcionada y por su autorización para publicar las fotografías de Pinguicula pilosa. A Jerzy Rzedowski y Victor Steimann por la revisión crítica del manuscrito.

\section{LITERATURA CITADA}

Casper, S. J. 1963. Gedanken zur Gliederung der Gattung Pinguicula L. Botanische Jahrbücher für Systematik 82(3): 321-335.

Casper, S. J. 1966. Monographie der Gattung Pinguicula L. Bibliotheca Botanica 127/128: 1-209.

Luhrs, H., M. Studnicka y O. Gluch. 2004. A new Mexican species of Pinguicula (Lentibulariaceae). Carnivorous Plant Newsletter 33(2): 43-46.

Studnicka, M. 1991. Interesting succulent features in the Pinguicula species from the Mexican evolutionary center. Folia Geobotanica et Phytotaxonomica 26: 459-462.

Zamudio, S. y A. Lux. 1992. Una nueva especie gipsícola de Pinguicula (Lentibulariaceae) de Nuevo León, México. Acta Bot. Mex. 20: 39-44. 